\title{
Frontier chemistry and materials for the twenty-first century, No. 3: preface
}

\section{San-Lang Wang ${ }^{1} \cdot$ Po-Shen Pan ${ }^{2} \cdot$ Chung-Hung Hsieh ${ }^{2}$}

Published online: 15 October 2018

(c) Springer Nature B.V. 2018

This special issue contains selected papers from the 3rd OPU-TKU International Symposium on Frontier Chemistry and Materials for the twenty-first century (3rd OPU-TKU), held in Sakai, Osaka, Japan, on November 19-20, 2015. Tamkang University (TKU) and Osaka Prefecture University (OPU) signed a sister university agreement in July 2012. In 2013, when Prof. Masakazu Anpo visited TKU, we decided to organize the first OPU-TKU International Symposium, which was held at OPU in November 18-19, 2013. The 3rd OPU-TKU followed the scope and spirit established by the previous two OPU-TKUs.

Development of new materials has recently become an extremely interesting research topic. Thus, we've decided to retain the original use of "Frontier Chemistry and Materials for the Twenty-First Century" as the main topic of the symposium.

The 10 papers included in this special issue give an idea of advances of our knowledge and capabilities in this research field. We wish to express our gratitude to the authors who submitted their excellent works to this special issue and all the reviewers who helped us to ensure the quality of the issue. We also very much appreciate the Editor-in-Chief of the journal, Prof. Masakazu Anpo, for accepting our proposal to publish this special issue.

San-Lang Wang

sabulo@mail.tku.edu.tw

Po-Shen Pan

popan@mail.tku.edu.tw

Chung-Hung Hsieh

chsieh@mail.tku.edu.tw

1 Life Science Development Center, Tamkang University, New Taipei City, Taiwan

2 Department of Chemistry, Tamkang University, New Taipei City, Taiwan 